\title{
The impact of urbanization and financial development on electricity intensity in China: Evidence from panel VAR approach
}

\author{
Ruijun Duan* \\ School of Economics and Commerce, Henan University of Technology, Zhengzhou, China
}

\begin{abstract}
This paper aims at exploring the impact of urbanization and financial development on electricity intensity in China during the period 2004-2018. By employing a panel vector autoregressive (VAR) approach, the study finds that the electricity intensity response to one standard deviation shock on urbanization shows a negative impact, and a positive shock to financial development initially increases electricity intensity and eventually decreases electricity intensity. Our analysis is important for policy makers for improving electricity efficiency planning and sustainable economic development policies.
\end{abstract}

\section{Introduction}

The world is facing the threat of global warming and climate change over the past three decades. Among many human activities that produce greenhouse gases, the use of energy is considered by far the largest source of emissions, and $\mathrm{CO} 2$ emissions from energy account for the largest share of global anthropogenic greenhouse gas emissions. Rising electricity demand was one of the key reasons why global $\mathrm{CO} 2$ emissions from the power sector are the largest increase. It is estimated that by 2040 , the power sector will account for $40 \%$ of global $\mathrm{CO} 2$ emissions [1]. As the World's largest $\mathrm{CO} 2$ emitter, China plays an important role in mitigating global climate change. Contribute to alleviating the global climate change, China has recently pledged to reach its peak of greenhouse gas emissions ahead of 2030[2]. Further improvement of electricity efficiency and low emissions generation technologies are important means to combat climate change. Therefore, it is of great importance to reduce electricity intensity for China's long-term sustainable development.

The literature on the impact of urbanization and financial development on energy intensity is relatively abundant. For example, [3] examined the relationship between urbanization and energy intensity in China, and found urbanization significantly increases energy intensity. [4] explored the impact of urbanization on energy intensity in twenty-two increasingly urbanized emerging economies, and the empirical result showed urbanization significantly increases energy intensity.[5] noted that Saudi Arabia's urbanization positively affects energy intensity in both the short term and the long term. [6] found that the direct impact of urbanization on China's energy intensity is generally positive while the indirect impact tends to be negative. In addition,[7] provided original findings that financial development decreases energy intensity in Europe and Central Asia.[8] revealed that financial development lowers energy intensity using the case of Ghana.[9] confirmed financial development are positively correlated and have a significant impact on the energy intensity level in the top ASEAN countries. However, as a subset of the more general literatures on energy intensity, very few studies have focused on finding the impact of urbanization and financial development on electricity intensity.

The objective of this paper is to use panel VAR model to empirically analyze the impact of urbanization and financial development on electricity intensity in China for a sample of 31 provinces for the years 2004-2018. The advantages of using a panel VAR approach is that by treating all the variables as endogenous, the panel VAR method help to alleviate the endogeneity problem. Further, the impulse response functions based on panel VAR estimations can account for the response of the deviation to shocks from the other variable in the long-run term, and panel regression cannot capture this dynamic effect.

\section{Empirical methodology}

In this paper, we use a panel VAR model with 31 Chinese provincial data to investigate the dynamic and endogenous relations among urbanization, financial development and electricity intensity during 2004-2018. The data is derived partly from the Almanac of China's Finance and Banking and partly from the China Statistic Yearbook of the related years. For simplicity, the definitions of related variables and the descriptive statistics of the data are illustrated in Table 1.

\footnotetext{
* Corresponding author: duanrj52058@126.com
} 


\subsection{Panel unit root tests}

If a series is non-stationary, it may lead to erroneous results before using them for further analysis[10]. For this purpose, this study employs three statistical methods to test the stationary and non-stationary conditions. They are HT test [11], IPS test[12] and Fisher-type test.

The HT test statistic is based on the OLS estimator, $\rho$, in the regression model

$$
Y_{i t}=\rho Y_{i, t-1}+Z_{i t}^{\prime} \gamma_{i}+\varepsilon_{i t}
$$

Where $Y_{i t}$ is a vector of endogenous variables: urbanization, financial development and electricity intensity; $Z_{i t}^{\prime} \gamma_{i}$ represents panel-specific means and trends; $\varepsilon_{i t}$ is white noise. Because the inclusion of panel means and time trends in the model may lead to biased estimates, the null hypothesis is not $\mathrm{H}_{0}: \rho=0$ but $\mathrm{H}_{0}: \rho=1$. The HT test assumes all panels share the same autoregressive parameters.

The IPS test uses the following panel ADF specification:

$$
\Delta \mathrm{Y}_{\mathrm{it}}=\rho \mathrm{Y}_{\mathrm{i}, \mathrm{t}-1}+\mathrm{Z}_{\mathrm{it}}^{\prime} \gamma_{\mathrm{i}}+\varepsilon_{\mathrm{it}}
$$

The IPS test differs from the HT test by relaxing the assumption of a common autoregressive parameter. The IPS tests the null hypothesis $\mathrm{H}_{0}: \rho_{1}=\rho_{2} \cdots \rho_{\mathrm{N}}=0$ (for all i) against the alternative hypothesis $\mathrm{H}_{1}: \rho_{1}=$ $\rho_{2} \cdots \rho_{\mathrm{N}_{1}}<0, \rho_{\mathrm{N}_{1}+1}=\rho_{\mathrm{N}_{1+2}} \cdots \rho_{\mathrm{N}}=0$ (for all i). Rejection of null hypothesis indicates no unit root.

The Fisher-type test combines the p-values from ADF or Phillips-Perron unit-root tests to obtain an overall test statistic whether the panel data contains a unit root. For a finite number of panels, The null hypothesis is that all panels contain a unit root, and the alternative hypothesis is that at least one panel is stationary. Under the alternative hypothesis, as $\mathrm{N} \rightarrow \infty$, the number of panels without unit root should grow at the same rate as N. [13]proposes the four methods to test the panel-specific unit-root. The first three methods differ in whether they use the inverse chisquared, inverse-normal and inverse-logit transformation of p-values, and the fourth is a modification of the inverse chi-squared transformation.

If positive residual cross-section dependence is not taken into consideration, panel unit root tests may possibly exist significant size distortions. To alleviate possible cross-section dependence, [14] suggested subtracting the cross-sectional means from the panel data before testing.

\subsection{Pedroni cointegration tests}

If it is found that the variables are $\mathrm{I}(1)$, then we can conduct co-integration tests. Pedroni (2004) proposes a residual-based test for the null of cointegration allowing for individual heterogeneous fixed effects and trend terms[15].Consider the following specification:

$Y_{i t}=\alpha_{i}+\delta_{i} t+\beta_{1 i} X_{1 i t}+\beta_{2 i} X_{2 i t}+\cdots+\beta_{k i} X_{k i t}+e_{i t}$

Where $\quad \mathrm{i}=1 \cdots \mathrm{N}, \mathrm{t}=1 \cdots \mathrm{T}, \mathrm{k}=1 \cdots \mathrm{K} \quad ; \quad$ The variables $Y_{i t}$ and $X_{i t}$ are assumed to be $\mathrm{I}(1)$, and residual $\mathrm{e}_{\text {it }}$ will also be $\mathrm{I}(1) ; \alpha_{\mathrm{i}}$ and $\delta_{\mathrm{i}} \mathrm{t}$ are fixed effects and time trend respectively; $\beta_{1 \mathrm{i}}, \beta_{2 \mathrm{i}}$ and $\beta_{\mathrm{ki}}$ are the cointegration slopes.

Table 1. Summary statistics of variables.

\begin{tabular}{|c|c|c|c|c|c|}
\hline Variables & Definition & Mean & Std. dev. & Min & Max \\
\hline ei & $\begin{array}{c}\text { The ratio of electricity consumption to GDP in 2004 } \\
\text { constant prices. }\end{array}$ & 0.1231 & 0.0939 & 0.0013 & 0.7246 \\
\hline urban & $\begin{array}{c}\text { The proportion of urban population to the total } \\
\text { population }\end{array}$ & 0.5141 & 0.1536 & 0.159 & 0.896 \\
\hline finance & The ratio of total credit to nominal GDP & 1.2834 & 0.7784 & 0.0114 & 6.9362 \\
\hline
\end{tabular}

To perform the cointegration test, we need to obtain the residuals from the equation (4) and then test whether the residual is $I$ (1) by the following residual equation:

$$
\hat{\mathrm{e}}_{\mathrm{it}}=\rho_{\mathrm{i}} \hat{\mathrm{e}}_{\mathrm{it}-1}+\mu_{\mathrm{it}}
$$

Various residual-based statistics is considered for testing the null hypothesis of no cointegration, namely, $H_{0}: \rho_{i}=1, \forall i$, where $\rho_{i}$ represents the coefficient of the estimated residual. The alternative hypothesis of the Pedroni tests is that the variables are co-integrated in all panels.

\subsection{Panel Granger causality test}

Dumitrescu and Hurlin(2012) expand on Granger causality test, and propose a method for testing panel causality[16]. The panel Granger causality test is as follows:

$$
Y_{i t}=\sum_{\mathrm{k}=1}^{\mathrm{m}} \beta_{\mathrm{k}} \mathrm{X}_{\mathrm{it}-\mathrm{k}}+\sum_{\mathrm{k}=1}^{\mathrm{m}} \gamma_{\mathrm{k}} \mathrm{Y}_{\mathrm{it}-\mathrm{k}}+\varphi_{\mathrm{t}}+\mu_{\mathrm{i}}+\varepsilon_{\mathrm{it}}
$$

Where $\beta_{\mathrm{k}}$ and $\gamma_{\mathrm{k}}$ are the parameters, $\varphi_{\mathrm{t}}$ is time trend, $\mu_{\mathrm{i}}$ is individual effect, $\varepsilon_{i t}$ is white noise. Dumitrescu and Hurlin construct Z-statistic to test the null hypothesis $H_{0}: \beta_{1}=\beta_{2}=\cdots=\beta_{\mathrm{k}}=0$. Rejection of the null hypothesis indicates Granger causality.

\section{4 panel VAR approach}

The panel VAR model combines the traditional VAR approach with the panel-data approach, which not only treats all the variables in the equation as endogenous, but also allows for unobserved individual heterogeneity[17]. The panel VAR model can be specified as follows:

$$
\mathrm{Y}_{\mathrm{i}, \mathrm{t}}=\mathrm{A}_{0}+\sum_{\mathrm{j}=1}^{\mathrm{P}} \mathrm{A}_{\mathrm{j}} \mathrm{Y}_{\mathrm{i}, \mathrm{t}-\mathrm{j}}+\mu_{\mathrm{t}}+\varepsilon_{\mathrm{i}, \mathrm{t}}
$$

Where $Y_{i, t}$ is $1 \times 3$ vector of endogenous variables including respectively the proxies of Urbanization, financial development and electricity intensity; $\mathrm{A}_{0}$ represents a vector of Intercept term, and $A_{j}$ is the coefficient matrix to be estimated; $\mu_{\mathrm{i}}$ is fixed-effects between different cross-sectional units, and $\varepsilon_{\mathrm{i}, \mathrm{t}}$ is error term.

The advantage of the panel VAR is to allow for the estimation of impact of one variable on orthogonal shocks on another, while holding all other variables constant. This is accomplished through the panel impulse-response function(IRF), which identify the response of one variable 
to the innovations in another variable in the system, while keeping all other shocks at zero.

\section{Results and discussion}

We check the stationary properties of the variables by using HT test, IPS test and Fisher-type test. The results shown in Table 2 indicate that except for urbanization, the null hypothesis of unit root is not rejected at the level form of variables, but can be rejected at the first difference form and all the variables become stationary at the $1 \%$ significance level. Thus, we can perform a cointegration test to examine whether urbanization, financial development and electricity intensity have a long-term relationship.

We have applied the Pedroni approach in order to test whether cointegration is present. The results reported in Table 3. It is noted that the statistics are significant rejecting the null hypothesis of no cointegration. This confirms the presence of a long-run relationship between urbanization, financial development and electricity intensity over the period 2004-2018.

Table 2. Results of panel unit root tests.

\begin{tabular}{|c|c|c|c|c|c|c|}
\hline & \multicolumn{2}{|c|}{ HT } & \multicolumn{2}{c|}{ IPS } & \multicolumn{2}{c|}{ Fisher-type(ADF) } \\
\hline & Intercept & $\begin{array}{c}\text { Intercept } \\
\text { \&trend }\end{array}$ & Intercept & $\begin{array}{c}\text { Intercept } \\
\& \text { trend }\end{array}$ & \multicolumn{2}{|c|}{$\begin{array}{c}\text { Intercept } \\
\text { \&trend }\end{array}$} \\
\hline ei & $0.5956^{* * *}$ & 0.1471 & $-2.7453^{* *}$ & $-3.0078^{* * *}$ & $1.5124^{*}$ & 0.1048 \\
& $(0.0000)$ & $(0.5585)$ & $(0.030)$ & $(0.0013)$ & $(0.0652)$ & $(0.4582)$ \\
\hline urban & $0.5871^{* * *}$ & $0.1256^{* * *}$ & $-2.1322^{* *}$ & $-7.6429^{* * *}$ & $39.4201^{* * *}$ & $70.7675^{* * *}$ \\
& $(0.0000)$ & $(0.0000)$ & $(0.0165)$ & $(0.0000)$ & $(0.0000)$ & $(0.0000)$ \\
\hline finance & $0.5987 * * *$ & 0.5854 & $-1.9005^{* *}$ & $-2.6503^{* * *}$ & 1.0468 & -2.4922 \\
& $(0.0000)$ & $(0.7114)$ & $(0.0287)$ & $(0.0040)$ & $(0.1476)$ & $(0.9937)$ \\
\hline $\mathrm{d}(\mathrm{ei})$ & $-0.0588^{* * *}$ & $-0.0530^{* * *}$ & $-8.9447^{* * *}$ & $-9.1351^{* * *}$ & $28.3049^{* * *}$ & $18.7211^{* * *}$ \\
& $(0.0000)$ & $(0.0000)$ & $(0.0000)$ & $(0.0000)$ & $(0.0000)$ & $(0.0000)$ \\
\hline $\mathrm{d}$ (urban) & $0.0116^{* * *}$ & $0.0792^{* * *}$ & $-12.0182^{* * *}$ & $-11.0346^{* * *}$ & $105.9659^{* * *}$ & $97.6542^{* * *}$ \\
& $(0.0000)$ & $(0.0000)$ & $(0.0000)$ & $(0.0000)$ & $(0.0000)$ & $(0.0000)$ \\
\hline $\mathrm{d}$ (finance) & $-0.0126^{* * *}$ & $-0.0095^{* * *}$ & $-8.6348^{* * *}$ & $-8.8660^{* * *}$ & $22.9505 * * *$ & $13.6125^{* * *}$ \\
& $(0.0000)$ & $(0.0000)$ & $(0.0000)$ & $(0.0000)$ & $(0.0000)$ & $(0.0000)$ \\
\hline
\end{tabular}

Note: p-values are presented in parentheses. ${ }^{* * *},{ }^{* *}$ and ${ }^{*}$ denote the significance at $1 \%, 5 \%$ and $10 \%$ level, respectively. $\mathrm{D}(\mathrm{)})$ is the first difference.

Table 3. Pedroni test for cointegration relationship

\begin{tabular}{|c|c|c|}
\hline & Statistic & p-value \\
\hline Modified Phillips-Perron t & 3.1099 & 0.0009 \\
\hline Phillips-Perron t & -1.7046 & 0.0441 \\
\hline Augmented Dickey-Fuller t & -2.3653 & 0.0090 \\
\hline
\end{tabular}

Note: H0: No cointegration. Ha: All panels are co-integrated.

Table 4. Granger-causality tests.

\begin{tabular}{|c|c|c|c|c|c|c|}
\hline & urban $*$ ei & ei $*$ urban & finance $\nRightarrow$ ei & ei $\nRightarrow$ finance & urban $\nRightarrow$ finance & financ $*$ urban \\
\hline Z-bar & $17.0769^{* * *}$ & $5.9031^{* * *}$ & $6.4014^{* * *}$ & $12.3617^{* * *}$ & $8.4857^{* * *}$ & $6.9976^{* * *}$ \\
& $(0.0000)$ & $(0.0000)$ & $(0.0000)$ & $(0.0000)$ & $(0.0000)$ & $(0.0000)$ \\
\hline Z-bar tilde & $8.0722^{* * *}$ & $2.1463^{* *}$ & $2.4106^{* *}$ & $5.5716^{* * *}$ & $3.5160^{* * *}$ & $2.7268^{* * *}$ \\
& $(0.0000)$ & $(0.0318)$ & $(0.0159)$ & $(0.0000)$ & $(0.0004)$ & $(0.0000)$ \\
\hline
\end{tabular}

Note: $\mathrm{p}$-values are presented in parentheses. ${ }^{* *},{ }^{* *}$ and $*$ indicate rejection of the null hypothesis at the $1 \%, 5 \%$ and $10 \%$ significance level, respectively.

For a better understanding, we further apply the Granger causality tests with the full sample. The results of the tests are summarized in Table 4 . Table 4 shows the existence of bidirectional causality relations between any two of urbanization, financial development and electricity intensity.

Fig.1 depicts the plots of the orthogonalized IRFs with a confidence interval of $5 \%$ to $95 \%$ using Monte-Carlo simulation with 200 replications. We start with the relationship between urbanization and electricity intensity. We note that the graph is below the zero line, which means that the electricity intensity exhibits a negative response to a standard deviation shock to urbanization. Besides, a standard deviation shock to urbanization, the electricity intensity initially decreases in period zero to 2 , and gradually rises and stabilizes in the long-run. The result implies that the improvement of urbanization increases the efficiency of electricity-use and reduced the electricity intensity by promoting technological progress. Next, we focus on the linkage between financial development and electricity intensity. We note that a shock of financial development creates a positive impact on electricity intensity initially, but this effect declines gradually from period 2 and have a negative impact after period 3 . The result means that in the early developmental stage, banks excessively expand 


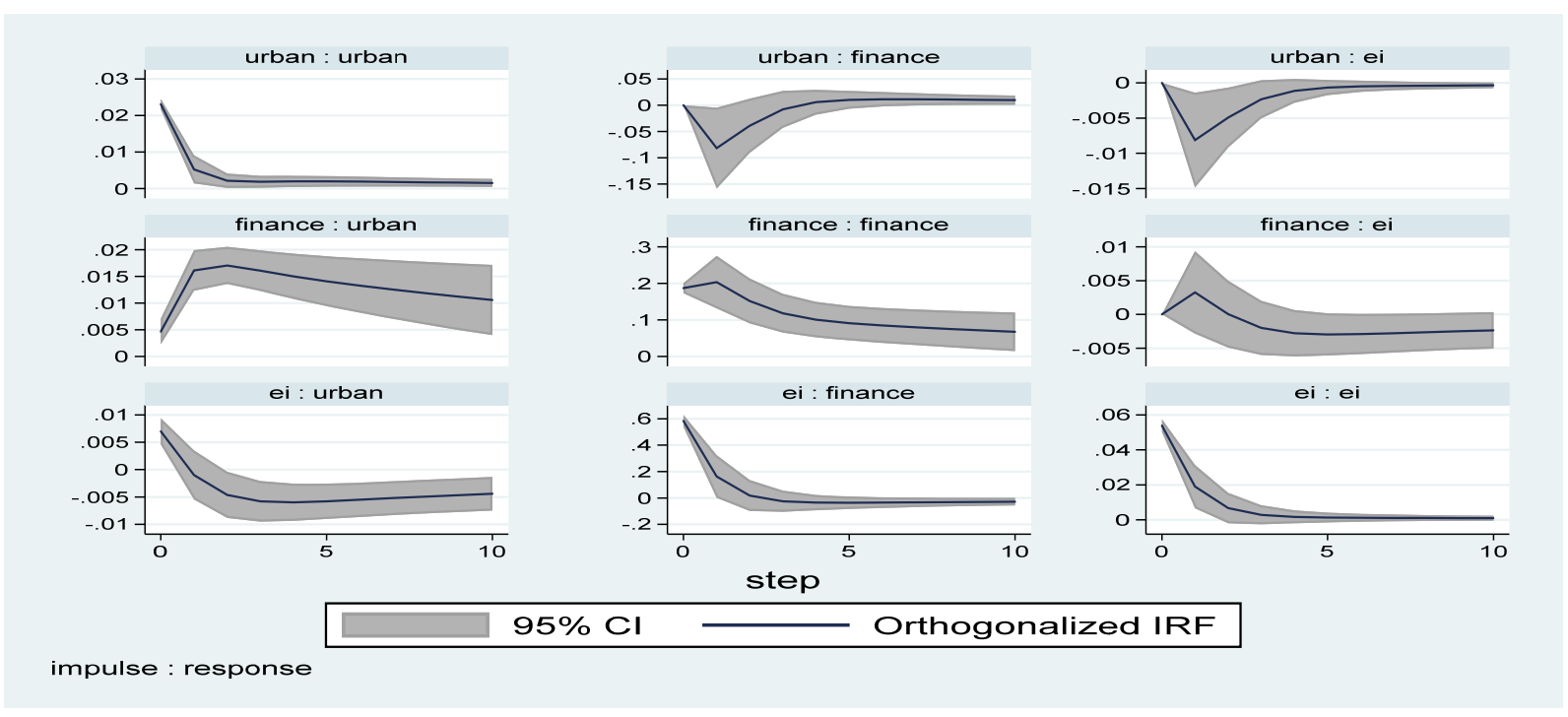

Fig. 1. The impulse response function plots.

the scale of loans, which stimulate electricity consumption by providing easy access of financial resources to households and thus increase electricity intensity. However, with the gradual improvement of financial efficiency, financial development will reduce the electricity intensity.

\section{Concluion}

Using Chinese provincial panel data from 2004 to 2018 of 31 provinces, the present paper utilizes panel VAR model to examine the dynamic impact of urbanization and financial development on electricity intensity. The empirical results reveal that there is bidirectional causality between any two of three variables. Further, the study finds that the electricity intensity response to one standard deviation shock on urbanization shows a negative impact, and a positive shock to financial development initially increases electricity intensity and eventually decreases electricity intensity.

Although urbanization seems to be conducive to decreasing electricity intensity, the influence is less. Therefore, if urbanization is considered an effective and consistent solution to decreasing electricity intensity, the policy to encourage further urbanization must focus on effective, green, and sustainable development. In addition, financial development should be used as a policy tool to lower electricity consumption by sanctioning loans at a cheaper cost to environmentally friendly industries that adopt advanced and energy-efficient technology during production processes.

\section{Acknowledgement}

This work is supported by the National Social Science Foundation of China (grant number 16BJY087).

\section{References}

1. IEA (2017): CO2 emissions from fuel combustion. www.iea.org/t\&c/

2. Shan Y, Liu J, Liu Z, Xu X, Shao S, Wang P, Guan D (2016): New provincial CO 2 emission inventories in China based on apparent energy consumption data and updated emission factors. Applied Energy 184, 742-750

3. Yan H (2015): Provincial energy intensity in China: The role of urbanization. Energy Policy 86, 635-650

4. Rafiq S, Salim R, Nielsen I (2016): Urbanization, openness, emissions and energy intensity: A study of increasingly urbanized emerging economies. Energy Economics 56, 20-28

5. Belloumi M, Alshehry A (2016): The Impact of Urbanization on Energy Intensity in Saudi Arabia. Sustainability 8,375

6. Elliott RJR, Sun P, Zhu T (2017): The direct and indirect effect of urbanization on energy intensity: A province-level study for China. Energy 123, 677-692

7. Bagayev I, Najman B (2014): Money to fill the gap? Local financial development and energy intensity in Europe and Central Asia. MPRA Paper No. 551934

8. Adom PK, Appiah MO, Agradi MP (2019): Does financial development lower energy intensity? Frontiers in Energy

9. Hussain HI, Slusarczyk B, Kamarudin F, Thaker HMT, Szczepańska-Woszczyna K (2020): An Investigation of an Adaptive Neuro-Fuzzy Inference System to Predict the Relationship among Energy Intensity, Globalization, and Financial Development in Major ASEAN Economies. Energies 13, 850

10. Rathnayaka RMKT, Seneviratna DMKN, Long W (2018): The dynamic relationship between energy consumption and economic growth in China. Energy Sources, Part B: Economics, Planning, and Policy 13, 264-268 
11. Harris RDF, Tzavalis E (1999): Inference for unit roots in dynamic panels where the time dimension is fixed. Journal of Econometrics 91, 201-226

12. Im KS, Pesaran MH, Shin Y (2003): Testing for unit roots in heterogeneous panels. Advances in Econometrics 115, 53-75

13. Choi I (2001): Unit root tests for panel data. Journal of International Money and Finance 20, 249-272

14. Levin A, Lin C-F, Chu C-SJ (2002): Unit root tests in panel data: asymptotic and finite-sample properties. Journal of Econometrics 108, 1-24

15. Pedroni P (2004): Panel Cointegration: Asymptotic and Finite Sample Properties of Pooled Time Series Tests with an Application to the PPP Hypothesis. Econometric Theory 20, 597-625

16. Dumitrescu E-I, Hurlin C (2012): Testing for Granger non-causality in heterogeneous panels. Economic Modelling 29, 1450-1460

17. Antonakakis N, Chatziantoniou I, Filis G (2017): Energy consumption, $\mathrm{CO} 2$ emissions, and economic growth: An ethical dilemma. Renewable and Sustainable Energy Reviews 68, 808-824 